\title{
Conceptual design studies for the European DEMO divertor: Rationale and first results
}

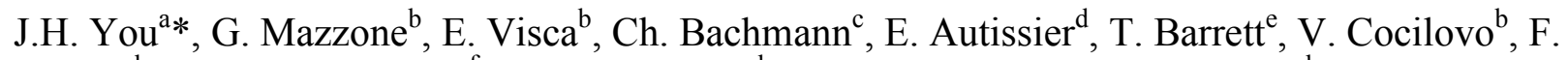

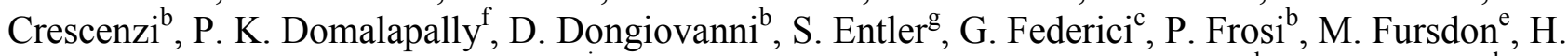 \\ Greuner $^{\mathrm{a}}$, D. Hancock ${ }^{\mathrm{e}}$, D. Marzullo, S. McIntosh ${ }^{\mathrm{e}}$, A. v. Müller ${ }^{\mathrm{a}}$, M. T. Porfiri ${ }^{\mathrm{b}}$, G. Ramogida $^{\mathrm{b}}, \mathrm{J}^{\mathrm{i}}$

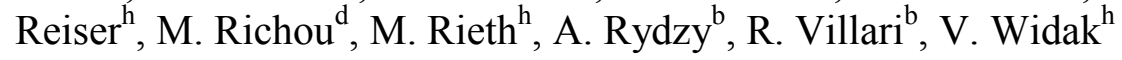 \\ ${ }^{a}$ Max Planck Institute for Plasma Physics, Boltzmannstr. 2, 85748 Garching, Germany \\ ${ }^{b}$ ENEA, Unità Tecnica Fusione, ENEA C. R. Frascati, via E. Fermi 45, 00044 Frascati, Italy \\ ${ }^{c}$ EUROfusion PMU, clo IPP, Boltzmann Str. 2, 85748 Garching, Germany \\ ${ }^{d}$ CEA, IRFM, F-13108 Saint Paul Lez Durance, France \\ ${ }^{e}$ CCFE, Culham Science Centre, Abingdon OX14 3DB, United Kingdom \\ ${ }^{f}$ Research Cnter Rez, Hlavni 130, 25068 Husinec - Řež, Czech Republic \\ ${ }^{g}$ Institute of Plasma Physics CAS, Za Slovankou 3, 18200 Praha 8, Czech Republic \\ ${ }^{h}$ KIT, IAM, Hermann-von-Helmholtz-Platz 1, 76344 Eggenstein-Leopoldshafen, Germany \\ ${ }^{i}$ CREATE, University of Naples Federico II, P.le Tecchio 80, 80125 Napoli, Italy
}

\begin{abstract}
In the European fusion roadmap, reliable power handling has been defined as one of the most critical challenges for realizing a commercially viable fusion power. In this context, the divertor is the key in-vessel component, as it is responsible for power exhaust and impurity removal for which divertor target is subjected to very high heat flux loads. To this end, an integrated R\&D project was launched in the EUROfusion Consortium in order to deliver a holistic conceptual design solution together with the core technologies for the entire divertor system of a DEMO reactor. The work package 'Divertor' consists of two project areas: 'Cassette design and integration' and 'Target development'. The essential mission of the project is to develop and verify advanced design concepts and the required technologies for a divertor system being capable of meeting the physical and system requirements defined for the next-generation European DEMO reactor. In this contribution, a brief overview is presented of the works from the first project year (2014). Focus is put on the loads specification, design boundary conditions, materials requirements, design approaches, and R\&D strategy. Initial ideas and first estimates are presented.
\end{abstract}

Keywords: DEMO, tokamak, divertor, plasma-facing component, conceptual design, Eurofusion

\section{Introduction}

In the recent European roadmap drafted for realizing commercially viable fusion power generation, reliable power handling was defined as one of the most critical missions [1]. In this regard, the divertor is the key invessel component, as it is responsible for power exhaust and impurity removal via guided plasma exhaust. Due to the intense bombardment of energetic plasma particles, the plasma-facing targets of the divertor are exposed to extreme heat flux loads. In addition, neutron irradiation produces defects and damage in the materials leading e.g. to embrittlement. Pulsed operation cause fatigue due to cyclic thermal stress variation. The complex and harsh loading environment a divertor is subjected to poses particularly challenging engineering issues that have to be solved for materializing a DEMO reactor. To this end, an integrated R\&D program has been launched in the framework of the EUROfusion Consortium in order to deliver holistic solutions of a conceptual design together with the core elements of required technologies for the entire divertor system of a DEMO reactor. The essential mission is to develop and verify advanced divertor design concepts and technologies being capable of meeting the divertor system requirements defined in the European DEMO reactor development (the so called DEMO 1).
In this article, a brief overview is presented on the project structure, objectives, rationales, approaches, and the first results obtained from the tasks carried out in 2014. The aim of this contribution is to provide readers with basic information on the current project activities and the background ideas of design approaches.

\section{EUROfusion work package 'Divertor'}

The divertor project (WPDIV) has been installed as a work package associated with the 'Power Plant Physics \& Technology' Department (PPPT) of the EUROfusion. WPDIV consists of two project areas: 'Cassette design \& integration' and 'Target development'. Fig. 1 shows the work breakdown structure. WPDIV is supported by a consulting panel of external experts who perform design progress review for the subproject Cassette (v.s.). The Project Board is mainly in charge of the surveillance of contractual progress and approval of major budgetary change or modification of scopes. As a part of PPPT, WPDIV is linked to other 12 work packages involved in PPPT via diverse technical interfaces. 6 leading research institutions in EU are participating in WPDIV. In total, a gross budget of 10 million euros were allocated for the first 5 years (2014-18), an extension of further 2 years is foreseen with additional budget. The delivery of the final Conceptual Design Report is due by end of 2020 . 


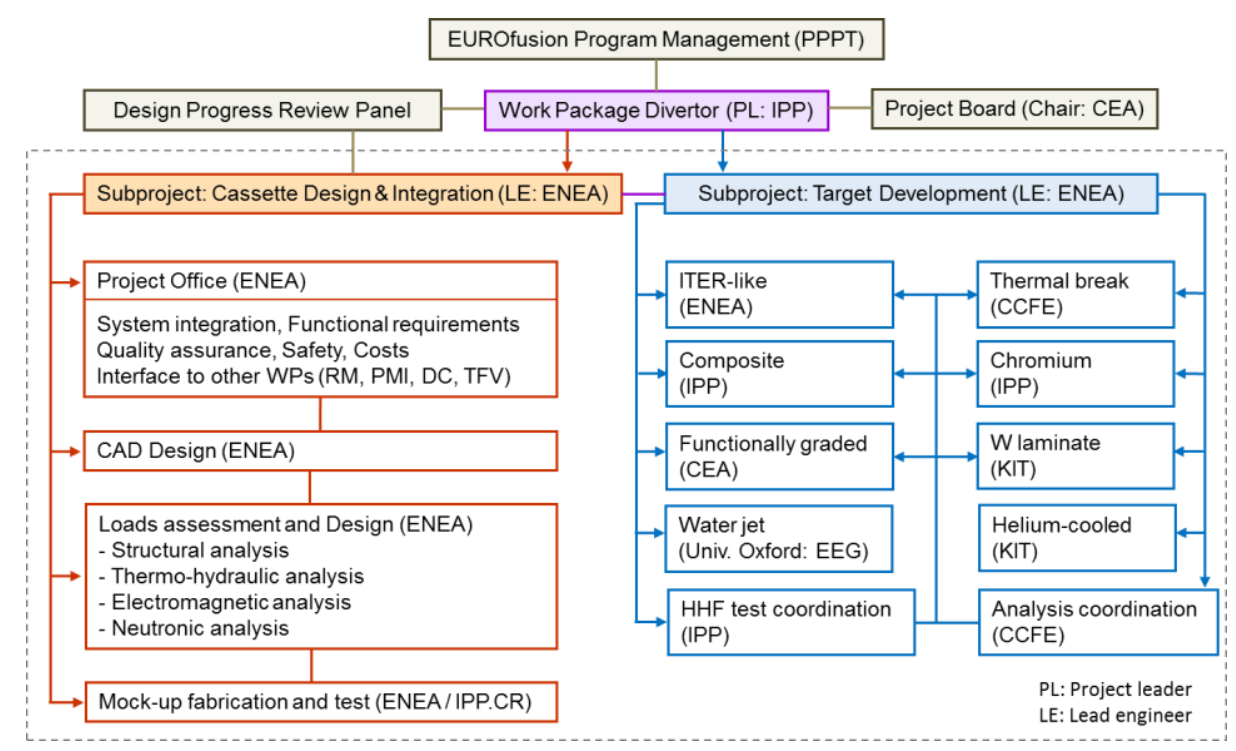

Fig. 1. Schematic project breakdown structure of the EUROfusion work package 'Divertor'.

\section{Subproject: Cassette design and integration}

\subsection{Baseline CAD models}

The initial design of a single divertor cassette was developed in 2014. This draft was essentially based on the ITER divertor design as plotted in Fig. 2 (a). In 2015 the divertor configuration was progressed deviating from the ITER design. In particular the size of the cassette was reduced and a separate cooling loop for the plasmafacing components was integrated. The interior details of the cassette are currently designed. Compared to the first version, the revised cassette model is characterized by a reduced volume. Both outboard and inboard baffle parts have been removed from the cassette while the breeding blanket has been extended instead. The tritium breeding ratio (TBR) is predicted to increase from 1.13 to 1.20 by the gain of the additional breeding areas.

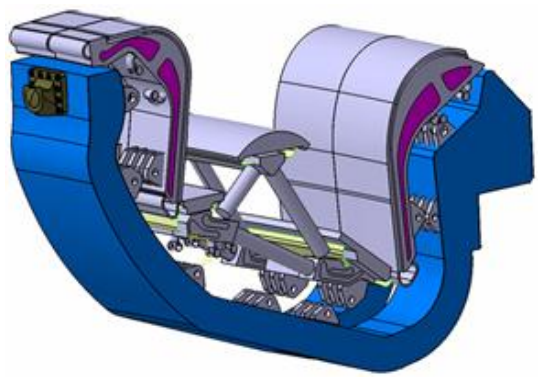

(a)

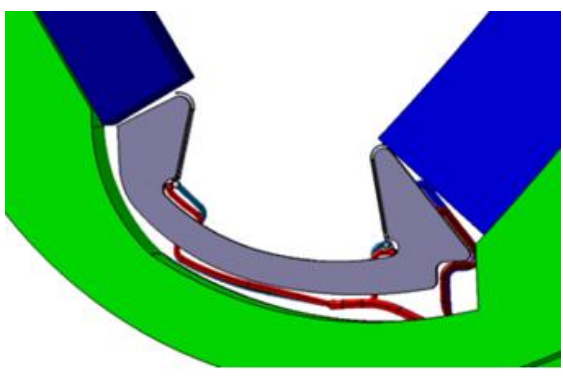

(b)

Fig. 2. CAD contour models of a single divertor cassette (a): $1^{\text {st }}$ version of year 2014, (b) $2^{\text {nd }}$ version of year 2015
For the time being the dome is not contained in the new CAD model for the sake of design simplification, but equipment of cassette with a dome is still considered as an option. A comparative study is ongoing to evaluate the impact of the absence of a dome. Decrease of neutral gas pressure, reduced efficiency of radiative cooling and pumping, potential gas flow toward the core plasma, and reduced shielding against neutron and heat flux are the primary issues. The issues are investigated together with the work package 'Tritium fuelling and vacuum'.

\subsection{Thermal loads: preliminary estimates}

As the current subproject is still situated in an early stage, a rigorous estimation of the expected loads is very difficult. The main reasons for this are that the physical boundary conditions and the operational scenarios have not been identified yet for DEMO and that the design of cassette interior has not been finalized yet. Nevertheless, first estimates of basic load parameters were produced to get a rough indication about loading features. The loads were categorized into 4 types: thermal, electromagnetic (Lorentz force), neutronic, and static. The particle loads from the plasma onto the surface causing sputtering and blistering are handled in the dedicated work package 'plasma-facing components'. As a starting basis thermal load parameters are assumed as follows [2]:

Total fusion power:

$2037 \mathrm{MW}$

Power for external heating: $\quad 50 \mathrm{MW}$

Power carried by radiating neutrons: $1630 \mathrm{MW}$

$9 \%$ thereof in divertor cassette: $\quad 147 \mathrm{MW}$

Total power radiated from the core: $238 \mathrm{MW}$ $10 \%$ thereof on divertor PFC: $24 \mathrm{MW}$

Plasma power extracted via scrape-off layer: $220 \mathrm{MW}$

$90 \%$ thereof dissipated by SOL radiation: $198 \mathrm{MW}$ $30 \%$ thereof on the divertor PFC: $66 \mathrm{MW}$

$10 \%$ exhausted by bombardment on target: $22 \mathrm{MW}$ $67 \%$ thereof on outer strike point: $15 \mathrm{MW}$ $33 \%$ thereof on inner strike point: $7 \mathrm{MW}$ where PFC stands for plasma facing components. 
Summing up the individual contributions to each part of divertor, thermal load partition is obtained as follows:

Total power deposited on divertor:

$259 \mathrm{MW}$

in cassette body:

$147 \mathrm{MW}$

on PFCs:

$112 \mathrm{MW}$

It should be noted that the strike points on the targets are subjected to the most intensive heat flux loads, since the thermal power density sharply peaks at these sites due to the narrow width of the strike band where the conducting SOL (a few mm thick) intersects. The heat flux profiles on the divertor PFCs and the peak heat flux density at the strike point could not be exactly specified yet, as the operation scenarios have not been defined. As a starting basis, the maximum local heat flux load of $10 \mathrm{MW} / \mathrm{m}^{2}$ at the strike point on the outer vertical target is assumed for stationary normal operation (5000 pulses during lifetime) and $20 \mathrm{MW} / \mathrm{m}^{2}$ for slow transient events (300 pulses), respectively. It is noted that the heat flux load parameters assumed for the DEMO divertor are identical to those of the ITER divertor [3].

\subsection{Nuclear loads: preliminary estimates}

Due to the absence of design details of cassette interior and lacking data on plasma operation parameters, it was not possible to make a precise neutronics analysis in this early stage of project. A rough preliminary assessment was made on the basis of the first cassette model with an ITER type PFC. The loading condition was extrapolated from that of the ITER divertor assuming a fusion power of $1600 \mathrm{MW}, 50 \%$ larger cassette size and twice higher neutron wall load. These assumptions are obsolete in the meantime, since the EUROfusion PPPT team revised the reactor design parameters of the DEMO tokamak system in 2015. Accordingly, the thermal power and its partition within the in-vessel components were modified as well.

The irradiation dose of the $\mathrm{Cu}$ heat sink and the $\mathrm{W}$ armor were predicted to reach up to 10 and $2 \mathrm{dpa}$, respectively, per full power year (fpy). The nuclear heating power due to kinetic neutron impact and gamma ray production was estimated to be $160 \mathrm{MW}$ in 48 cassettes (inner target: 39 MW, outer target: $56 \mathrm{MW}$, dome: $39 \mathrm{MW}$, and body: 27 MW). In the revised cassette design model of year 2015, total nuclear heating was estimated to be $147 \mathrm{MW}$ in 54 cassettes. Neutronics analysis shall be updated following up the design progress.

\subsection{Materials and the operation temperatures}

The baseline PFC armor material for DEMO divertor is tungsten. As baseline structural materials copper alloy $\mathrm{CuCrZr}$ has been chosen for the PFCs and ferritic steel Eurofer97 for the cassette body, respectively.

The selection of $\mathrm{CuCrZr}$ alloy (or $\mathrm{Cu}$-base composites) as heat sink material of the PFC is owing to the excellent thermal conductivity and superior mechanical properties required for a structural application such as strength and ductility at envisaged operation temperatures [4]. Such an ideal combination is the unique and exclusive merit of $\mathrm{CuCrZr}$ alloy or copper-base composites being attractive for the high heat flux region of the divertor PFCs.
It is noted that each of these materials are subject to a recommended service temperature range to avoid critical embrittlement, when operated under neutron irradiation [5]. For $\mathrm{CuCrZr}$ alloy the lower service temperature limit under irradiation lies between $150{ }^{\circ} \mathrm{C}$ and $250{ }^{\circ} \mathrm{C}$. The exact specification of this temperature limit depends on the specific structural design criterion to be applied for design. When uniform elongation is used as criterion, the limit should be $250{ }^{\circ} \mathrm{C}$, whereas it is set $150{ }^{\circ} \mathrm{C}$, in case the total elongation criterion is considered [4, 5]. The physical basis of the ductility requirement is the ability of irradiated $\mathrm{CuCrZr}$ alloy to undergo thermal recovery of lattice defects. The recommended upper temperature limit is $350{ }^{\circ} \mathrm{C}$ for long term operation [5]. This limit is determined by strength loss due to thermal softening and irradiation creep.

In this judgment, the guiding design rationale is to assure sufficient ductility and strength without sacrificing the required margin to the critical heat flux (CHF) or the envisaged HHF loads.

The permissible operation temperature range for the PFCs may be determined by three major factors: 1) the maximum allowable coolant temperature which is low enough for preventing coolant burnout at critical events, 2) the minimum allowable heat sink temperature which is high enough to avoid severe irradiation embrittlement and 3) the maximum allowable heat sink temperature which is low enough so that the loss of tensile strength remains still acceptable. The degree of conservatism adopted for the structural design would influence the decision on the temperature limits.

A further constraint related to the heat sink application of $\mathrm{CuCrZr}$ alloy is the issue of corrosion erosion which may occur on the inner wall of cooling tube to a serious degree, when the wall temperature is above $200{ }^{\circ} \mathrm{C}$ and the water chemistry is not properly controlled [6].

For massive cassette body, the reduced activation $9 \mathrm{Cr}$ steel Eurofer97 is considered as structural material. The motivation of using this steel for cassette is to exploit the essential benefits of the superior low activation feature to allow recycling of the material within a due period (say, a couple of centuries).

As structural material, Eurofer97 steel is also subject to a recommended service temperature range to avoid brittle failure caused by irradiation embrittlement or undesired creep-fatigue interaction. When irradiated, the ductile-tobrittle transition temperature (DBTT) of Eurofer97 steel is shifted up to $200{ }^{\circ} \mathrm{C}$. Thus, it is generally desired to operate the steel cassette above the DBTT to prevent any brittle failure. But the lower temperature limit of Eurofer steel can be still decreased, if the peak stress intensity is not significant and the irradiation dose is not high [7].

With regard to the lifetime of the PFC tungsten armor, the intensive physical interactions between the incident edge plasma particles and the armor surface pose diverse and critical material issues. The most prominent damage features are erosion, melting and cracking. Erosion takes place due to sputtering, blistering, fuzz formation and dust formation. Cracking occurs either on microscopic (by ELM-like thermal shock fatigue) or macroscopic (by 
extreme heat flux load of about $20 \mathrm{MW} / \mathrm{m}^{2}$ ) length scale. The issues of plasma-wall interaction such as erosion, redeposition or tritium retention belong to the scope of the work package "Plasma-Facing Components" (WPPFC).

\subsection{Cooling schemes}

\subsubsection{Rationale for the cooling conditions}

In the design framework of the early DEMO (also called DEMO 1), only a water-cooled divertor is considered as baseline design concept.

The conceptual layout design of the piping systems for the water cooling of cassette has been currently devised. Initially, two different options were under consideration. The first option is single coolant circuit applied in series to both the PFCs and cassette body. The second option is dual separate coolant circuits each applied independently to the PFCs and cassette body, respectively. Each option has its pros and cons. In the course of design evolution, it turned out that the cooling option with dual separate coolant circuits is suited better for the present case where different materials are used for cassette body and PFCs. It is also advantageous in terms of pressure drop and power conversion efficiency.

The cooling parameters of coolant at inlet are as follows:

- temperature: $150{ }^{\circ} \mathrm{C}$ (or lower)

- pressure: $5 \mathrm{MPa}$

- velocity: $16 \mathrm{~m} / \mathrm{s}$

- tube diameter: $12 \mathrm{~mm}$ (with swirl tape)

The parameters were derived from the thermohydraulic condition to assure the minimum required power exhaust capability of the target to cover the operational scenarios of the divertor. The design goal was to reach a sufficient thermal margin to the local CHF to prevent bulk boiling and burnout accident even at slow transient events. The envisaged heat flux margin to the local CHF at the tube ranges from 1.3 to 1.6 depending on the given geometry of a target PFC. It is noted that the current set of cooling parameters allows the local CHF value of $48 \mathrm{MW} / \mathrm{m}^{2}$. In Fig. 3, the calculated values of local $\mathrm{CHF}$ at the tube are plotted as a function of coolant temperature and coolant velocity for a fixed coolant pressure $(5 \mathrm{MPa})$ and a tube diameter $(12 \mathrm{~mm})$ with a swirl tape.

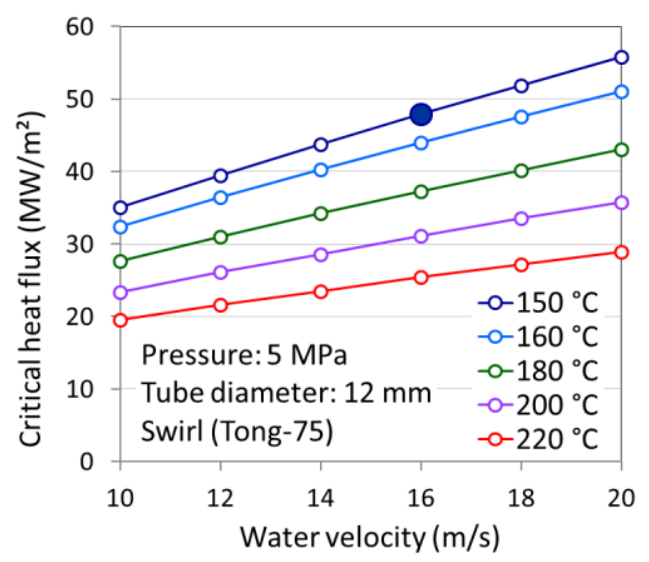

Fig. 3. Calculated local CHF values at the tube plotted as a function of coolant temperature and coolant velocity.

\subsubsection{Thermohydraulic analysis for the 2014 model}

In the first project year, where an ITER-like divertor was considered, a preliminary conception of cooling scheme was produced for the divertor version of year 2014. The single coolant circuit concept was adopted. A schematic drawing of the cooling scheme is illustrated in Fig. 4. In this scheme, the streaming sequence of the coolant is as follows: inlet at outboard cassette body, outboard target, outboard baffle, outboard cassette body, inboard cassette body, inboard target, inboard baffle, inboard cassette body, dome umbrella, and finally outlet.

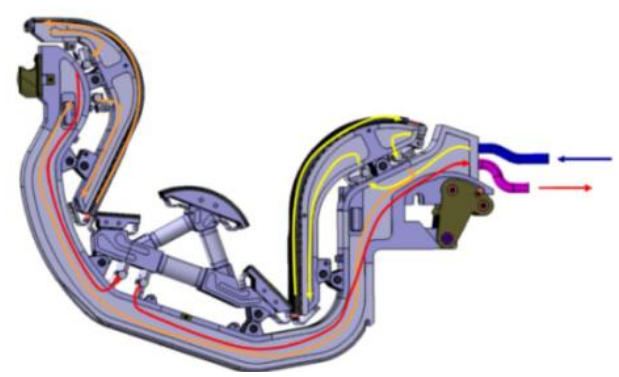

Fig. 4. Schematic drawing of preliminary cooling scheme devised for the ITER-like divertor (first version of year 2014).

A preliminary thermohydraulic analysis has been carried out for the first cassette model of year 2014 by means of computational fluid dynamics analysis. For this, threedimensional FEM (finite element method) models were created for the tubular cooling channel and the coolant distributor manifold. The estimated cooling parameters are summarized in Table 1.

Table 1. Estimated thermohydraulic performance of the single coolant circuit cooling concept (the $1^{\text {st }}$ cassette model in 2014).

\begin{tabular}{|l|c|c|c|}
\hline & OVT $^{1}$ & IVT $^{2}$ & Dome $^{3}$ \\
\hline No. of PFC units per cassette & 50 & 30 & 19 \\
\hline Tube diameter $(\mathrm{mm})$ & 12 & 14 & $/$ \\
\hline Tube roughness $(\mu \mathrm{m})$ & 1.4 & 1.4 & 1.4 \\
\hline Power in the PFCs $(\mathrm{MW}){ }^{4}$ & 92.8 & 59.5 & 46.5 \\
\hline Swirl tape length $(\mathrm{m})$ & 0.7 & 0.6 & $/$ \\
\hline Twist ratio & 2 & 2 & $/$ \\
\hline Tape thickness $(\mathrm{mm})$ & 0.8 & 0.8 & $/$ \\
\hline Inlet water velocity $(\mathrm{m} / \mathrm{s})$ & $16-17$ & $20-21$ & 15.5 \\
\hline Mass flow rate per pipe $(\mathrm{Kg} / \mathrm{s})$ & 1.8 & 2.7 & tbd. \\
\hline Gross mass flow rate $(\mathrm{Kg} / \mathrm{s})$ & 4008 & 4008 & 4008 \\
\hline Inlet pressure $(\mathrm{MPa})$ & 5 & 3.93 & 1.92 \\
\hline Outlet pressure $(\mathrm{MPa})$ & 3.93 & 2.1 & 0.26 \\
\hline Pressure drop $(\mathrm{MPa})$ & 1.1 & 1.8 & 1.84 \\
\hline Pressure drop by swirl tape & 0.37 & 0.4 & $/$ \\
\hline CHF margin & 1.84 & 1.56 & tbd. \\
\hline Inlet temperature $\left({ }^{\circ} \mathrm{C}\right)$ & 150 & 155.4 & 158.8 \\
\hline Outlet temperature $\left({ }^{\circ} \mathrm{C}\right)$ & 155.4 & 158.8 & 161.5 \\
\hline Temperature increase $\left({ }^{\circ} \mathrm{C}\right)$ & 5.4 & 3.4 & 2.7 \\
\hline
\end{tabular}

${ }^{1}$ OVT, ${ }^{2}$ IVT: outboard and inboard vertical target

${ }^{3}$ hypervapotron

${ }^{4}$ The values do not match with the latest estimates given in sec. 3.2 , as the assumed reactor parameters are different.

The results of thermohydraulic analysis manifest that the cooling via a single/serial coolant circuit is not adequate for the given cassette system due to the facts that: 
1. the total pressure drop is unacceptably large,

2. the coolant temperature in the cassette body is not high enough for irradiated Eurofer steel to be operated in fully ductile regime [8].

To solve the issues, the coolant channels need to be laid out separately, one for the PFCs and one for the cassette body. Thus, the single/serial coolant circuit concept was abandoned, and the concept of dual separate coolant circuit is further pursued. This requires each cassette having 4 instead of 2 feeding pipes which might cause more complication in cassette maintenance.

\subsubsection{Cooling scheme for the 2015 model}

In the second project year (2015) a revised CAD model of cassette has been created. A major design change was implemented: the outboard and inboard baffles were cut off from the cassette while the breeding blanket modules were extended to cover the previous baffle regions [2]. The motivation of this design change was to increase the TBR by exploiting the high dose areas of PFCs suitable for breeding. The cassette is shaped in accordance with the kinematic envelope required for remote maintenance. The design and the CAD model creation of the interior structure of the Cassette body are still ongoing.

Accordingly, the cooling scheme was updated as well. At the moment, three different kinds of piping schemes with dual circuits are currently considered as illustrated in Fig. 5. Cooling parameters are to be specified in near future for the PFCs and cassette body, respectively. The cooling condition for the PFCs will not be altered. In the case of cassette body, the DBTT of irradiated Eurofer steel will be taken into account for the specification.

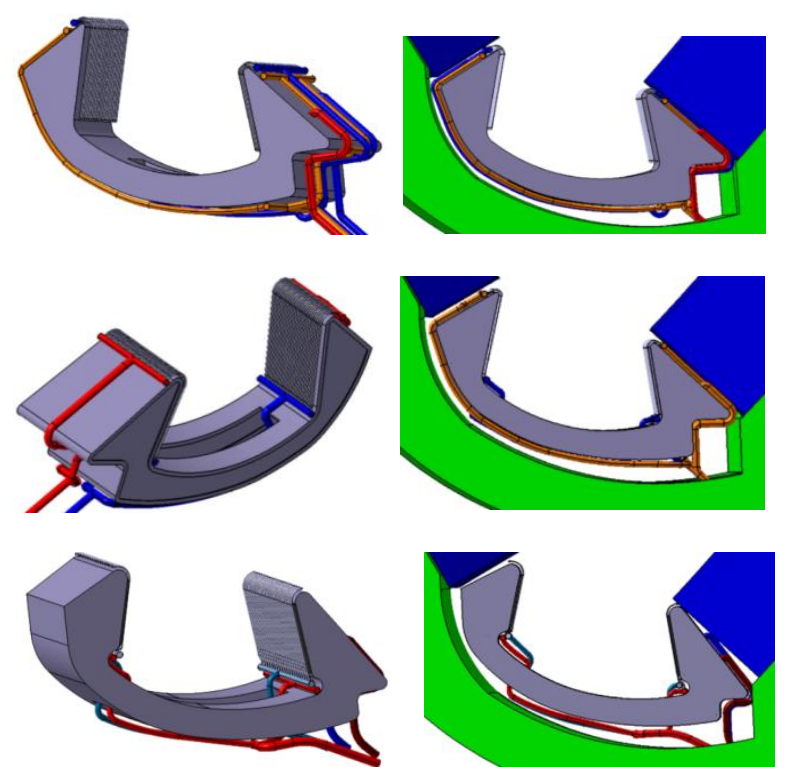

Fig. 5. Three different piping schemes for cassette cooling based on dual separate coolant circuits (model of year 2015).

\section{Subproject: Target development}

\subsection{Design rules for the monoblock type target}

As there are no suitable structural design rules being specifically applicable to a monoblock-type target with a brazed structure, dedicated elastic structural design rules have been developed together with analysis guidelines. Plastic structural design rules are currently being worked out. The objectives of the elastic structural design rules are to provide standardized criteria against major failure modes on the basis of characteristic loading natures and failure features being found in monoblock-type targets. In addition, a generic computational procedure has been defined for comparable FEM analysis. Strictly speaking, only the coolant tube is a structural part being subject to the structural design rules.

In the current elastic analysis procedure, the $\mathrm{CuCrZr}$ tube is assumed to be elastic while the copper interlayer is assumed to be elasto-plastic. In this way elastic rules can be applied to the pipe while still including the effects of the plastic flow in the copper interlayer. The tungsten armour block is assumed to be elastic as non-structural part. It is only to be used for an initial design assessment. A rigorous design assessment will be provided later by the elasto-plastic analysis procedure and design rules.

Only elastic structural design rules determined from differential stress are considered (ratchetting, fatigue). These rules are found to remain valid irrespective of the considerable residual stress expected from monoblock manufacture. Further, three thermal rules were defined: maximum heat flux at the coolant tube wall, and the peak temperatures in the tube as well as armour. In case substantial residual stress is present, actual strains can hardly be accurately computed within the elastic frame. Due to this essential limitation, the elastic rules should be regarded as provisional design criteria.

\subsection{Design concepts for target PFCs}

One of the major challenges for developing a reliable target for DEMO divertor is to find a heat sink material that is able to fulfill the relevant structural design criteria at the irradiation dose level and the heat flux load range foreseen for the DEMO divertor. It seems that $\mathrm{CuCrZr}$ alloy could not fully meet the material requirements (e.g. irradiation creep above $350{ }^{\circ} \mathrm{C}$, irradiation embrittlement below $250{ }^{\circ} \mathrm{C}$ ) [5]. In this project, various kinds of $\mathrm{Cu}-$ $\mathrm{W}$ composite materials, novel interlayer materials and dedicated design rules are employed. Furthermore, a $\mathrm{Cr}$ monoblock concept with $\mathrm{W}$ armor is also investigated.

Table 2. Design concepts for DEMO divertor target and dome being considered in EUROfusion WPDIV.

\begin{tabular}{|l|l|l|l|}
\hline Concepts & Tube & Interlayer & Monoblock \\
\hline ITER-like & $\mathrm{CuCrZr}$ & $\mathrm{Cu}$ & $\mathrm{W}$ \\
\hline Thermal break & $\mathrm{CuCrZr}$ & $\mathrm{Cu}$ felt & W \\
\hline Composite & $\mathrm{W}_{\mathrm{f}} / \mathrm{Cu}$ & $\mathrm{Cu}$ & $\mathrm{W}$ \\
\hline Chromium & $\mathrm{CuCrZr}$ & $\mathrm{Cu}$ & $\mathrm{Cr}(\mathrm{W}$ tile $)$ \\
\hline Graded $\mathrm{W} / \mathrm{Cu}$ & $\mathrm{CuCrZr}$ & $\mathrm{W} / \mathrm{Cu}$ & $\mathrm{W}$ \\
\hline W laminate & $\mathrm{W} / \mathrm{Cu}$ & $\mathrm{Cu}$ & $\mathrm{W}$ \\
\hline
\end{tabular}


In Table 2, the design concepts for DEMO divertor target being currently employed in the WPDIV are listed with description of the respective heat sink materials. The underlying idea of innovation is either to enhance the material performance in terms of high-temperature strength (W wire-reinforced $\mathrm{Cu}$ composite tube, $\mathrm{W} / \mathrm{Cu}$ laminate tube) or to reduce thermal stress (thermal break, graded), DBTT (chromium), or heat flux concentration at tube (thermal break). The designs are based mostly on $\mathrm{W}$ monoblock geometry (except the chromium PFC).

For some target design concepts, the materials and test mock-ups have been successfully fabricated. Figs. 6 - 9 show four examples of such mock-ups each equipped with a W/Cu laminate composite cooling tube, thermal break interlayer made of a porous $\mathrm{Cu}$ felt material, an infiltrated $\mathrm{W} / \mathrm{Cu}$ composite monoblock bonded with $\mathrm{W}$ tile armor (in the figure cooling channel is not machined yet), and $\mathrm{W}$ wire-reinforced $\mathrm{Cu}$ composite cooling tube (only the tube is shown), respectively. It is noted that the illustrated composite target mock-ups (or tubes) were fabricated by means of industrial processes in industrial manufacture scales.

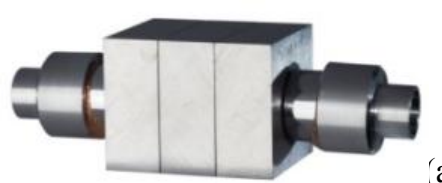

(a)

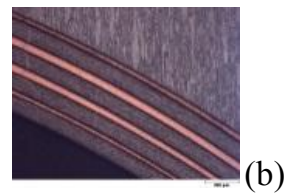

Fig. 6. (a) Divertor target mock-up equipped with a W/Cu laminate composite tube, (b) metallographic section.
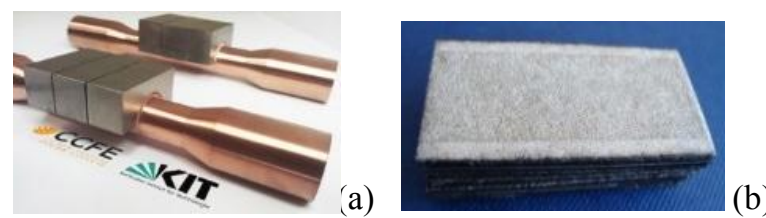

Fig. 7. (a) Divertor target mock-up with a thermal break interlayer, (b) porous $\mathrm{Cu}$ felt material used as thermal break.
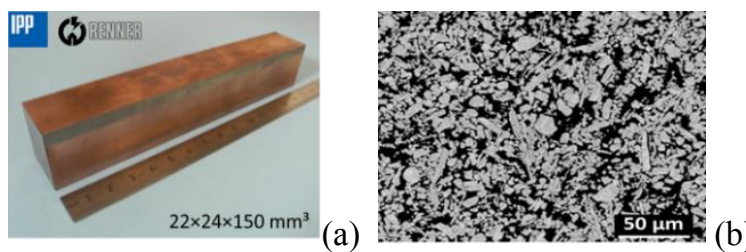

Fig. 8. (a) Divertor target mock-up consisting of $\mathrm{W}$ flat tile armor (5 mm thick) and monoblock made of infiltrated $\mathrm{W} / \mathrm{Cu}$ composite, (b) microstructure of the composite (SEM image).
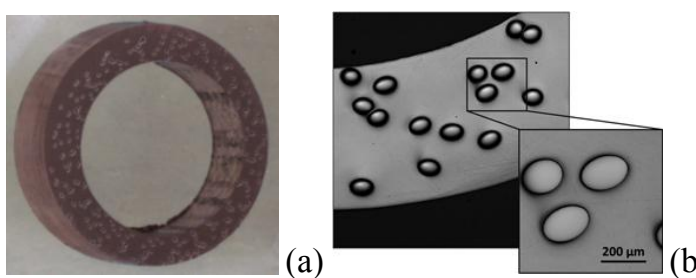

Fig. 9. (a) A cut piece of a composite cooling tube (200 $\mathrm{mm}$ long) made of $\mathrm{W}$ wire-reinforced $\mathrm{Cu}$ matrix composite, (b) metallographic section.

\section{Summary}

In order to produce the conceptual design of DEMO divertor, an integrated R\&D work package WPDIV was launched in 2014 in the framework of the EUROfusion Consortium PPPT program. The WPDIV consists of two subprojects: 'Cassette design \& integration' and 'Target development'. For specifying the loading features, first computational analyses (thermohydraulic, neutronic and structural etc.) were carried out in 2014 using the initial ITER-like cassette model. In 2015, the second round of analyses has been continuing using the revised cassette model created in 2015 where the previous baffle regions were removed from the cassette body and attached to the breeding blanket in order to increase the tritium breeding ratio. Currently, three different variants of cooling circuit schemes are designed. A separate, dual coolant circuit system is considered, where two parallel piping systems are applied each for the target PFC or the cassette body, respectively, with different operation temperatures. As near term option, only water cooling is considered, while helium cooling is regarded as a long-term option.

The optimal cooling conditions for the target PFC and the rationale for PFC design were derived from the envisaged maximum thermal power density at the strike point of the vertical target. In order to enhance the target PFC performance, several advanced design concepts are under development. Here, composite heat sink materials or novel interlayer materials play an essential role.

\section{Acknowledgments}

This work has been carried out within the framework of the EUROfusion Consortium and has received funding from the Euratom research and training program 2014-2018 under grant agreement No 633053. The views and opinions expressed herein do not necessarily reflect those of the European Commission.

\section{References}

[1] F. Romanelli et al., Fusion Electricity: A roadmap to the realization of fusion energy, EFDA, 2012.

[2] C. Bachmann et al., Issues and strategies for DEMO in-vessel component integration, ISFNT 2015 paper

[3] R.A. Pitts et al., J. Nucl. Mater. 438 (2013) S48.

[4] J.H. You, Copper matrix composites as heat sink materials for water-cooled divertor target, Nucl. Mater. Energy, DOI: 10.1016/j.nme.2015.10.001.

[5] J.H. You, A review on two previous divertor target concepts for DEMO: Mutual impact between structural design requirements and materials performance, Nucl. Fusion 55 (2015) 113026 (11pp).

[6] J. Öijerholm et al., Erosion corrosion of $\mathrm{CuCrZr}$ specimens exposed for simulated ITER operational conditions, Nucl. Mater. Energy (submitted).

[7] E. Materna-Morris et al., J Nucl. Mater. 386-388 (2009) 422-425.

[8] E. Gaganidze et al., KIT Scientific Report 7596, KIT Scientific Publishing, 2011. 